\title{
Methodological principles of piano technique in the stages of development
}

\author{
Rumyana Stoyanova Zhekova-Stoynova \\ Plovdiv University "Paisii Hilendarski", Plovdiv, Bulgaria
}

Email address:

rumiana_zhekova@abv.bg

\section{To cite this article:}

Rumyana Stoyanova Zhekova-Stoynova. Methodological Principles of Piano Technique in the Stages of Development. International Journal of Literature and Arts. Special Issue: Musical Theory, Psychology and Pedagogy. Vol. 2, No. 5-1, 2014, pp. 42-48. doi: 10.11648/j.ijla.s.2014020501.17

\begin{abstract}
The technique of the performer's movements is determinant to the quality of keyboard performance. The performer's motor development is achieved, in accordance with the stages of age development. The author of this article presents the methodological principles of work in mastering the keyboard movements. Motor skills have age defined characteristics. They functions in a relation to the anatomic and psychophysiological profile of the performer. Their comprising components have different indexes in the separate stages of individual development, which is a direct requirement for a change in the methodological approaches. The piano pedagogue needs to find opportunities to influence the biopsychological potential of the students for processing motor information, to activate it to the maximum extent with the purpose of achieving a quality musical activity as an interpreter. The pedagogic selection of models for motor development should be based on the current profile of the student and should reflect the hierarchical principle of building complex movements. The refinement of methods for pedagogical influence aims at achieving optimal pianist movements with a free command of the body; realization of the interrelation between the state of the piano playing apparatus and the qualities of the achieved sound result; mastering of the motor parameters - strength, temporal and spatial; building skills for constructing motor programs, which correspond to the semantic purposes and achieve a logical and vivid interpretation of the work; improving the sensory-motor coordination during the performance of the motor programs.
\end{abstract}

Keywords: Piano, Movements, Motor Parameters, Children, Teenagers, Young Adults, Methods of Education

\section{Introduction}

Piano performance has a proven benefit for everyone who studies this instrument - for the ones, who dedicate themselves to a professional career as performers, as well as for those, for whom the piano is a means of musical education and training. The beginning of learning to perform on the piano can take place in different stages of the individual development. Each definitive life stage has specific characteristics, which are determinant for the selection and application of the methodological principles and approaches in education. The characteristics of age differentiate the instrument training advantages, which should be made use of, from the disadvantages, on which a concrete pedagogical influence should be focused and refined.

\section{Aim}

The main aim of the author of this article is to present the methodological principles, in accordance with the students' age, of work for teaching the keyboard movements on the piano. Motor skills have age-specific characteristics. They function in a relation to the anatomic and psychophysiological profile of the performer. Their comprising components have different indexes in the separate stages of individual development, which is a direct requirement for a change in the methodological approaches.

The piano pedagogue needs to find opportunities to influence the biopsychological potential of the students for processing motor information, to activate it to the maximum extent with the purpose of achieving a quality musical activity as an interpreter. The pedagogic selection of models for motor development should be based on the current profile of the student and should reflect the hierarchical 
principle of building complex movements.

The knowledge of the psychophysiological patterns of forming of the functional capabilities of the brain, of the perceptions, of the memory, etc. help to create efficient models for building piano motor skills and habits with the aim of acquiring a quality interpreter's technique with an overall psychomotor stability, directed at a creative, adequate to the author's conception, performance of the piano work. The pedagogic priorities in building the piano technique are: a) achieving a rational organization of the movements; b) mastering the temporal, spatial and strength parameters of the movements; c) acquiring a psychophysiological coordination of the movements.

\section{Tasks for Achieving the Goal}

The analysis of the students' age in an anatomic-physiological and psychological aspect forms a different view on the conditions, logic, structure and contents of the piano training. It directs us to the creation of appropriate to the age models for mastering the piano playing movements, through practice and consolidation of specific musical performance actions, as well as the gradual expansion of the independency, self-control and level of initiative in that regard. Stimulated through the activation of psychological processes - senses, perceptions, attentive and mnemonic processes, is the creation and application of motor programs, which provide step-by-step meaningful interaction with the instrument. As a result of the gradual complexification of the motor tasks, the processes of acquiring specific motor skills and habits become more dynamic.

In piano performance, the interpreter goals of the pianists are realized through the movements of the hands and the precise contact of the fingers with the keyboard. Related to the motor aspect of the performance is also the mastering of the pedalization as an extremely specific piano means of expression. In this way, through the movements of the hands, feet and the whole body, a variety of interpreter actions and a complex coordination between them is created, with the goal of taking control of the keyboard space.

\section{Age Characteristics of the Anatomic Development}

When building piano playing motor skills, the age of the performer should be considered. If the student is in their teenage years and is starting to learn the piano, it must be taken into account that it is a period, in which the motor apparatus has already been developed and it is not that flexible and susceptible to training, as in children. The piano playing apparatus as part of the musculoskeletal system of the person includes a passive (bone) and an active (muscle) part. The so called "bone age" is determined by the centers of ossification of the arm. The ossification in human development is completed as follows: in the clavicle, scapula and humerus - at 20 - 25 years of age; radial bone 21 - 25 years; ulna (elbow bone) - 21 - 24 years; wrist -10 13 years; palm -12 years; phalanges of the fingers $-9-11$ years. The early age of the ossification of the wrist, palm and fingers points out to the following:

The optimal age for beginning the piano training is childhood, at 5 - 6 years of age, due to the following reasons:

- the piano playing motor apparatus at that age is still unstabilized and susceptible to influence;

- this age is the sensitive period for activities with music;

- an early beginning is needed for the prolonged process of acquiring and mastering the piano movements and their improvement.

- With beginner pianists, who are adolescents and young adults, since they have a completely mature motor apparatus, the pedagogue is faced with the following tasks:

- achieving a correct posture of the hands, which will stimulate the learning of motor skills;

- taking to account the personal characteristics of each individual, regarding the typology of the hand, its mobility and the elasticity of the fingers, wrists and hands, the length of the fingers, etc.;

- applying methods for the activization of the psychological processes for the intensification of the motor skills and their transformation into psychomotor skills. This complex process starts at the moment of acquaintance with the keyboard and continues through all of the stages of learning the performance art.

\section{A Characteristic of the Psychological Processes, According to the Age}

In teenagers and young people, the cognitive psychological processes are found in the so called optimum, which, together with the strong individual motivation, present conditions for a successful beginning of the training in an instrument.

Piano training should be thus based on the associative-logical character of the thinking of young people, on the vast capacity of their memory, on the stability of their attention and their ability to allocate it, on the fine process of emotional reflection, on their personal motivational needs and will.

The larger experience, gathered through the senses, i.e. the higher sensitive culture of young people, allows the piano pedagogue to use their ability to compare and account for the results in regard to the qualities of the sound with different methods of sound production. The now "helpful" memory of the student allows for long-term memorization of the guidelines for the ways of playing when overcoming different motor difficulties when performing.

different motor difficulties when performing.

An especially important moment, facilitating the 
achievement of results with teenagers and young people, is the capability of thinking over, assessment and self-control when consciously learning the movements.

On the other hand, the very training in piano actively improves all psychological processes of the individual, while musical learning presents wide opportunities for active intellectual development of the student, because this is derived directly from its specifics.

A mandatory requirement for modeling new specific movements is the application of all pedagogical methods with an accent on those, which are appropriate for the age. In teenagers and young people, these address mainly the intellect. Verbal explanations have a leading importance in creating the motor culture of young people, since they possess abilities to quickly and thoroughly process the information. As a supplementary method, personal pedagogical demonstrations are also applied, in order for the student to combine the intellectual comprehension of the movement with the immediate sensory perceptions. Trained in this area are self-observation and self-control, so that abilities are built for the neutralization of appearing tension in the different groups of muscles in the hands, legs and body. When learning the piano playing motor skills, the causes for failures have to be analyzed and the methods for their elimination have to be explained, at the same time the movements have to be interpreted as means of reaching the artistic goals.

According to the conclusions of psychologists about the processes of learning all individual stages of development, an essential moment is the presence of a stimulus. This is an important guideline in the pedagogical activity. As stimuli for provoking interest in playing the piano, the following are applied:

- familiarizing with musical material, which the performer likes, which has an influence on them and which they would like to perform. From this it follows that the pedagogue should research carefully the interests of the students;

- participating in a collective performance of music, as a accompanists or a member of a band. In this way, the student receives and additional stimulus, because of the induced feeling of responsibility to the group;

- including the student in a pedagogical play situation in a technical difficulty, how would they explain to a student the means and methods for overcoming difficulties and achieving greater success rate.

\section{Piano Playing Motor Skills}

The motor skills represent a highly integrated structure of an extreme complexity and dynamics of the functional connections. Motor skills as psychophysiological structure are formed in life in the course of the individual development of the person during their whole life cycle, not only during the period of growth, i.e. in childhood. The large quantity of interfunctional relations of the psychomotor skills is emphasized by the fact that the motor analyser does not exist isolated and is inextricably connected to the processes of metabolism and the general life activity. The indicators of strength, tremor, coordination and accuracy of movements, as well as the indicators of speed and dexterity, are found in a certain interrelation, defined by the general biological specifics of the human as an individual, as well as by the characteristics of the activities they engage in. The age dynamics of the psychomotor structure and the correlation connections of the motor skills with the other functions, the change in quantity and the correlation of the interfunctional connections in the stages of individual development have to be accounted for and considered by the piano pedagogue.

Psychophysiological systematic formations are characterized by dynamics, while, in the piano instrumental training, they are subject to active stimulation. In the process of development of the piano player activity, the motor skills of the performer are improved and adopt features of operativeness. An ease of the transition from the auditory to the other modalities appears: the auditory-spatial and auditory-motor connections are sharpened, the coordination is improved.

When motor skills are subject to constant influence in the process of focused training, which is performed in learning to play an instrument, a specialized motor development is achieved. When playing the piano, specialized movements with divers characteristic, various strength, spatial and temporal parameters are created through the retaining and stimulating neuron processes.

\section{Parameters of Clavier Motor Skills}

The temporal component is manifested in the temporal accuracy of the movements and the endurance of the motor apparatus of the pianists - the ability for continuous work without lowering the level of quality. The speed of movements is a variation of the temporal component. Speed is expressed in the increase of the frequency of the manifestation of the movements in a performance of a musical work in a fast tempo. It is often called dexterity.

The temporal component includes also the processes for maintaining a constant tempo when performing, for achievement of a steady acceleration or deceleration.

The pressure on the performer's apparatus of the pianists is significant. In a relation to this, considered as part of the temporal component is also the endurance of the hands (manual endurance), as well as the endurance of the whole organism during a prolonged performance of fast movements (in musical works with faced-paced tempos with increased requirements for the performance of technically complex sequences).

When there are failures to achieve the exact temporal parameters of the piano movements in recreating the metro-rhythm, the motor learning is impeded. In such cases, the pedagogue has to identify the specific motor problem and to offer measures for its overcoming. It is possible that an inexpert allocation of the attention between the tasks of 
the two hands is present. It is possible that in sequences of assonances, the student has not determined whether there are common, repeating tones, for which the fingers do not need to move or which will be used as a guide point for the movements of the others (up or down, sequential or with a larger stretch, or with a transition of the hand, etc.), to be delayed with the visual projection of a specific leap, to have not anticipated the rational allocation of the fingers between the white and black keys, etc.

The strength component in the movements of pianists is related to muscle energy. The quality and the dynamics of sound, the so called "sense of the keyboard" depend on the accumulated energy and the produced strength of the muscles.

In children - beginner pianists, the dynamic specter in performance is poorer and highly narrowed in the zones of the "forte" dynamic, while in young people during the initial stage of education in piano, thanks to the prominent muscle mass and the good intermuscular coordination, the saturation and brightness of sound is easily achieved, but on the other hand, it is harder to nuance the sound production in the "piano" dynamics. The muscle strength of the pianist apparatus grows in the process of the systematic work of the piano player on the exercises and musical works, i.e. strength depends on systematic activities with the instruments, their duration and ways of acquiring - the repertoire should lead to accumulation strength in different parts of the pianist's motor apparatus.

The appearing states of tension in the muscles of the hands represent often found prerequisites for technical failures in the piano performance. To master these states, it is necessary to build the correct posture, through which the presentation of unwanted pressure in the muscles of the body can be eliminated. Since the pianist is focused on many new performer's tasks, they are unable to notice the appearance of tension in a specific spot in the hands or body. The sensations of tension in different muscles are not subject to their attention and they do not notice them, while this impedes the development of the appropriate motor programs. In these moments, the role of the piano pedagogue is necessary and decisive. The problem of learning and application of relaxation as a type of technique for the achievement of naturalness is not a subject to a detailed research, while many pedagogues leave finding ways of coping with the pressure on the piano playing apparatus to the students alone, since they do not considered it to be a condition for an imperfect performance and technical failures. Sometimes the performance of a certain clavier work could be technically correct, with no visual or auditory painful processes of tension, undergoing in the motor apparatus of the performer, being perceived. But the achieved in this way performance, with "tension" in the performer's apparatus, not being noticed by the teacher and not being subject to training of habits and skills for relaxation and self-control, often is a precondition for the worsening of the problem and the beginner pianist does not have the prospect for a proper technical development. In the more advanced stages of training, performed in this way, the appearance of illnesses of the hands is possible, for example different muscle and joint inflammations, etc. For the optimal technical realization of the conceptual sound image, the rational application of the processes for activation of the muscle energy and the processes of relaxation of pressure by the performer is of crucial importance. The coordination of the two processes and the building of clear self-awareness in this regard need to be trained still in the beginner stage of instrument playing development. Mindful control of the level of pressure and the relief of the muscles during the rehearsal work leads to the formation of automatic control, which on its turn later on releases the performance's attention from the observation of this process.

For beginner piano players, mastering each movement is connected to the improvement of intramuscular coordination. The unskilled initial attempts in performance of the most basic movement, for example the performance in "non legato" of a single voice gradual movement with one finger of one hand, are owed to the undeveloped intramuscular coordination, focused at the performance of such a fine specialized movement, concentrated on the application of a single finger contact with the keyboard.

The interaction of the participating in the movements muscles represents the intramuscular coordination and it is specific to the individual types of movements and cannot be transferred from one movement to another. At the beginner stage, the intramuscular coordination of the movements of the performer should be a subject to special pedagogical care The more advanced intermuscular coordination leads to an increase of the manifested power, speed, endurance and flexibility. The rigidness, the excessive tension in the motor apparatus, the fast fatigability of the muscles are related to the inaccurate intermuscular coordination and the lack of the appropriate correction, which reflect negatively on the quality of all performance movements.

In modern piano pedagogy, the freedom of movement is understood as an organized coordination of the relevant neuromuscular functions of the organism. The alteration of tension and release, pressure and relaxation of the pianist's apparatus is of utmost importance for the quality of the performance.

The spatial component of the movements limits the work field and is manifested in the abilities of the piano player to manage their movements, to coordinate them, to measure and commensurate. The work on the spatial component aims at correct functioning and achievement of an interanalyser auditory-visual-motor synthesis for accuracy and success in positioning on the keys of the instrument, based on the visual-motor coordination, and at the realization of auditory control (nuancing of the sound), based on auditory-motor and tactile-motor coordination.

The largest part in the structure of sensor-motor coordination of pianists is played by the auditory-motor coordination. The foremost importance of the auditory-motor coordination has been highlighted in practically all works, dedicated to the performer's technique. 
As Isai Aleksandrovich Braudo writes: “...hearing is connected not only to the knowledge of the performer, but to a great extent also to the movement of his hands. The last relation is too diverse" (, ...слухът е свързан не само със знанието на изпълнителя, а в голяма степен и с движението на ръцете му. Последната връзка е твърде многообразна") [1, p. 220].

The improvement of auditory-motor coordination in the process of piano training is predetermined by the type of visual signals. Note signs, reading sheet music on two staves during the beginner stage of the development of the pianist technique creates specific problems, related to mastering of the process of decoding graphically encoded note text into semantic auditory and motor units. Knowledge of the psychophysiological processes, related to reading, gives opportunities for applying the correct pedagogical techniques. When reading, the goal is to accelerate the appearance of auditory notions, after the visual perceptions, acquired through the sheet music. They are the conditions for a correct motor reaction. The notions should include whole semantically connected groups of tones, for fast comprehension of the logic of the musical construction. The action of this system, based on the visual-hearing-motor skills synthesis, is achieved with the active participation of the attention, the mental processes and the memory. In her book "Psychological Principle in the Performer's Art" [6, p. 5], Tamara Yankova writes the following: "For the performer, the note text plays the role of a stimulus, which influences the visual analyser and activates certain brain centers. Impulse waves are sent from them mainly to the auditory and correspondent motor and tactile zones, which prepare the auditory notions and at the same time bring into a state of readiness and activate the individual appendages of the whole body” („Нотният текст за музиканта се явява като дразнител, който въздейства върху зрителния анализатор и оживява определени мозъчни огнища. От тях се отправят импулсни вълни предимно към слуховите и съответните двигателни и тактилни области, които подготвят слуховите представи и същевременно привеждат в готовност и действие отделните крайници на цялото тяло” ) [6, p. 5].

\section{Types of Performance Movements}

In the initial stage of education, the work on the movements begins by learning the different articulations non legato, legato, staccato. Used for the learning of a new articulation are short tonal combinations, after which the sequences are extended. In legato, for example, two sounds are combined at first, "shifting" from finger to finger, after which this combination should be performed with a single movement of the hand, i.e. releasing - pressing. In this way, the initial habits for playing in legato are formed.

In a short staccato, the sound is made with active final phalanges of the fingers. The sharp sound production causes a fast and elastic jump of the finger from the hand up to a specific point, while the height of the high point depends on the tempo, strength and character of the tone. In the high point, the hand is curved and starts to relax. The relaxation, the lowering does not represent free fall, but a controlled, restrained movement.

In the lowest point, also without stopping, the finger sharply produces the next tone and the same process is repeated. In a faster movement, this principle of jumping while constantly moving the hand is kept, only the height of lifting the hand is shortened. The faster the tempo is, the greater the role, played by the connecting movements of the hand.

In the initial stages of piano training, first to be learnt are the movements of the fingers, then added are the unifying movements of the hand. Practice shows that the most comfortable and natural are the movements, done with the "whole arm", from the shoulder joint.

When seeking economy of movements, the hand should move smoothly and uninterrupted, assuring the most comfortable position for each finger. In combinations with black keys, the wrist can rise. In this way, it actively interacts with the fingers. At the same time, the active fingers strictly limit the movements of the wrist and prevent it from shaking, loosening. Namely, this represents the useful freedom of the wrist. Because of such interaction, the unneeded swing of the fingers and the excessive movements of the wrists are eliminated and an economy and efficiency of movements is achieved.

The fingers that have played, together with the wrist, are travel in the direction of the movement, trying to condense, narrow the position of the hand. Thanks to this, the first finger is found in the most comfortable position for moving under, and $3^{\text {rd }}$ and $4^{\text {th }}$ - for going over the first (in the reverse movement). At the moment of transitioning, the hand seamlessly shifts in the direction of the movement and gives the opportunity for the first finger to freely approach the next key, press it without a push and without additional swinging from the wrist. Because of the closeness of the fingers and the incline of the hand towards the side, the transfer of the second finger is also in an appropriate position for a smooth transition through the first finger over the shortest path (without an unneeded swing).

When alternating short figurations, within the limits of a single position (for example, for short arpeggios), the thumb in an upwards movement and the fifth finger, moving downward (right hand), should be brought to the first key of the subsequent group, so to be prepared, without pressing it yet.

These ways of moving the hand, bringing together the fingers, transitioning the thumb and transferring through it the $2 \mathrm{nd}, 3 \mathrm{rd}$, 4th fingers protect the technique of the pianists from angularity, abrupt transitions, unneeded accents, excessive movements of the hands and fingers. This sets conditions for fluidity, wholeness of the movements and tone uniformity.

It is necessary to combine the freedom of the hands and fingers with their organization and discipline, and also the intensity and continuity of movements - with economy and 
efficiency. The choice of fingering has an important significance in technical work.

It should be chosen mindfully - this simple requirement is often forgotten by the beginners. When reading, for many of them the fingering remains on the background. When playing in a slow tempo, the accurate fingering escapes the attention. In this way, incorrect fingering is learnt. And only later on, with the transition to the real tempo, its unsuitability is found.

Certain fingering "formulas" have been formed in the performer's practice. When learning such formulas for scales and arpeggios, the beginners also develop certain motor habits. The correspondent motor stereotypes are formed, which facilitate automation and consolidation of the movements. They help in learning the "texture formulas", encountered in musical works.

However, when studying a musical work, the performer does not always have to use only the traditional fingerings, but needs also to choose the one that is most suited for the artistic image. The pedagogue should teach the beginner the fingering concepts and, alongside the student's acquaintance with the traditional fingering, direct them to use all types of varied fingering, according mostly to the artistic purposes. The pedagogic principles of fingering are mainly aimed at:

- mindful attitude towards the markings;

- consideration of the individual characteristics of the student;

- consideration of the tempo of the work;

- the writing should not be whole, but only provide guidelines;

Successful motor development is achieved in the conditions of gradual complexification of the keyboard composition of the musical works. In this way, learning the movements for mastering the spatial plane is performed in stages, while the main indicator is the texture of the musical pieces, included in the work material.

The texture (in Latin, "facture" - preparation, building or the Latin word "facio" - to do, to accomplish) organizes in an artistic uniformity all of the means of expression of the musical language and provides an overall complete look of the work. Texture differentiates and unifies in vertical, horizontal and depth a whole range of components, whose analysis is an important condition still at the stage of familiarization of the beginner with the sheet music for each piece, and has a direct influence on the development of the piano performing movements.

The approach for mastering and perfecting the motor skills should be connected with the choosing and finding of the appropriate keyboard exposition of the musical works for beginners. Some of the essential moments are:

1 Learning minimalist finger movements. The types of minimalist techniques have been developed most thoroughly in the beginner's educational material. A characteristic trait of them is the stable position allocation of the technical figures. All five figures are positioned on the degrees in a fifth (quint) position. In this most comfortable positioning, the fingers are in a natural, unforced state, allowing the development of a habit for, in equal parts, smooth and more dexterous performance.

2 Helpful for the simultaneous development of the techniques for both hands are the symmetrically placed technical figures in the staffs for both hands, performed with a synchronized matching fingering.

3 An important role is given to learning a scale technique. The work is performed in two directions: overcoming difficulties in the position and learning the transition to a new position.

4 Position playing - as a starting point in the development of the technique. A significant amount of figures from the minimalist technique, presented in a form of short uniform in rhythmical and technical structure positioning cores, repeated over the course of the whole work or in its long episodes.

In order to overcome technical difficulties, it is needed to create an ability in the student for identification of the difficult places and for transforming them through variation into technical exercises - i.e. they should be able to create "templates" on their own and turn them into motor habits. For whatever types or variations of motor technique, learning comes down to developing motor skills. The performance of chords, octaves, finger figurations, trills, etc. - all elements are connected to the acquisition of motor skills. The more motor skills the pianist has developed, the wider and manifold their scope, the more dexterous and flexible they are, the more stable, that much more the development of the motor skills will be successful.

The motor technique is formed in different types of performer's activity - for example, with detailed work on one type or other of musical works. An efficient way of developing motor habits is training with special technical exercises. This truth has long been revealed and confirmed from the experience of many generations of pianists. The exercises lead, along the shortest path, to acquiring the most commonly found texture formulas and combinations. Practicing, the pianist develops stable, firmly consolidated ways of performing specific piano playing activities. They should find on their own the most comfortable, plastic piano movements, which they should seek mindfully, focusing on this task, experimenting and selecting only the most needed ones through the mechanisms of self-observation and self-control. The search for comfortable positions and finer motor sensations is an important process. The hands should be adapted to a different textural pattern, appropriate positions should be sought, aiming to relieve the difficult, to facilitate the complex; the uncomfortable should be made natural and acceptable.

As a conclusion for the above-stated, we have to summarize that the technique of the performer's movements is crucial for the quality of clavier performance. Its acquisition and development should be based on methods of full and free command of the body, knowledge of the anatomic-psychological specifications of the pianist apparatus and the mechanisms of organization of the 
movements. This gives an opportunity for analyzing in detail the movements, for comprehending the reasons of the appearance of inconvenience in the motor production of sound images, to find the shortest and most corresponding ways for neutralizing these causes and to seek the optimal piano movements.

The piano teacher should therefore know well the psychophysiological bases of the organization of movements, the actions of the psychological processes during performance, structure and functions of the piano playing apparatus, in order to refine the methods of pedagogical influence and to teach motor abilities as speed of movements, dexterity, strength, endurance, coordination. The entire motor system is managed, regulated and coordinated by the nervous system, in a close interrelation with the rest of the systems - aspiratory, circulatory and others. The relationship between mental and motor skills is straight and for that reason education should be directed at the development of the psycho-motor skills of the student. We need to emphasis on the importance for the pedagogue to study the psychological mechanisms of the manifestation of motor skills, to which belong the functions of determining, measuring, reproduction and differentiation of spatial, temporal and strength parameters of movement, as well as their coordination.

\section{Conclusions}

As a conclusion of the exposition, in the present article, the following methodological principles are formulated for the development of the clavier technique:

1 Clavier motor development is performed, in accordance with the stages of age development. The clavier motor skills are formed on different levels of construction of the movement in a hierarchal aspect: from the realization of the muscle-strength and intermuscular coordination through the sensor-motor relations to the semantic image goal;

2 Individualization of the methodological principles for learning the movements;

3 Mastering of the motor parameters - strength, temporal and spatial;

4 Realizing the interrelation between the state of the piano playing apparatus and the qualities of the achieved sound result.

5 Building skills for constructing motor programs, which correspond to the semantic purposes and achieve a logical and vivid interpretation of the musical work;

6 Improving the sensory-motor coordination during the performance of the motor programs.

\section{References}

[1] Braudo, I. Articulation (On Pronunciation of Melody), "Musical Horizons" Magazine, Issue 11-12, Sofia, 1982. (Браудо, И. Артикулацията (за произношението на мелодията), сп. Музикални хоризонти, бр. 11-12, София, 1982).

[2] Fileva, K. Methodology of Teaching Piano. Plovdiv, 2011. (Филева, К. Методика на преподаване на пиано. Пловдив, 2011).

[3] Gardner, Howard, Intelligence Reframed: The Multiple Intelligences of the 21th Century. Siela, Sofia, 2004. (Гарднър Хауърд Нова теория за интелигентността: Множествените интелигентности на 21 век. Сиела, София, 2004).

[4] Liberman, E. Work on the Piano Technique. Klassika - XXI, Moscow, 2007. (Либерман, Е. Работа над фортепианной техникой. Классика- XXI, Москва, 2007).

[5] Shmidt-Shklovskaya, A. A. Of Teaching Pianist Habits. Klassika - XXI, Moscowa, 2009. (Шмидт-Шкловская, А. А $\mathrm{O}$ воспитании пианистических навыков. Классика- XXI, Москва, 2009).

[6] Yankova, T. Psychological Principle of the Performer's Art. Nauka i Izkustvo, Sofia, 1967. (Янкова, T. Психичното начало в изпълнителското изкуство. Наука и изкуство, София, 1967). 